\title{
'Linguistic Diversity on TV': A Program for Developing Children's Multiliteracies Skills
}

\author{
Eleni Griva \\ University of Western Macedonia \\ Correspondence concerning this article should be addressed to Eleni Griva, University of Western \\ Macedonia, 3 Ikaron, Kozani 501 00, Greece. E-mail: eegriva@uowm.gr
}

\begin{abstract}
Katerina Maroniti
Researcher

Correspondence concerning this article should be addressed to Katerina Maroniti, Aristotle University of Thessaloniki, University Campus, 54124, Thessaloniki, Greece.
\end{abstract}

\author{
Anastasia Stamou \\ Aristotle University of Thessaloniki \\ Correspondence concerning this article should be addressed to Anastasia G. Stamou, Aristotle University \\ of Thessaloniki, University Campus, 54124, Thessaloniki, Greece.
}

\begin{abstract}
In this article, we present a program designed for and carried out with young children, which was based on the four-stage multiliteracies model: experiencing, conceptualizing, analyzing and applying creatively. The main purpose of the study was to develop children's critical awareness of linguistic diversity through popular culture texts in a collaborative, creative and multimodal educational environment. The program was carried out for two school years: a) in the first school year, an intervention was implemented to $2^{\text {nd }}$ grade children of a Greek primary school, and b) in the second school year, a similar intervention was applied to children of the $1^{\text {st }}$ grade. In this article, we report on the results of the first school year's intervention. The results revealed the positive impact of the program on children's ability to easily distinguish between different types of speech styles due to geographical, age and socio-economic factors. The children understood - at least to some extent - that the texts of popular culture tend to display language diversity in a distorted and stigmatized way. The results of those implementations were very encouraging; a fact that stimulates our interest in continuing respective ventures by involving a wider sample of students and incorporating a greater range of popular culture texts.
\end{abstract}

Keywords: linguistic diversity, young children, popular culture texts, multiliteracies skills, critical language awareness

New social conditions and technological developments since the early 2000s have created the need for individuals to acquire new skills in order to be able to function successfully in the modern educational and social environment. These innovations lead to new forms of literacy, often referred to as 21st century literacy, resulting in the necessity for developing students' multiliteracies skills in order to respond effectively to new digital environments.

Consequently, multiliteracies have emerged from the need to develop the necessary skills to understand multimodal texts integrating different semiotic ways to generate meaning and to understand the meanings produced in multiplex/multidimensional and multicultural contexts (Kress \& Van Leeuwen, 1996). Multiliteracies also create a different type of pedagogy in which language and other semiotic resources are dynamically representational sources that are constantly shaped by their users as they employ them to achieve certain cultural goals (Cope \& Kalantzis, 2000). In multiliteracies pedagogy, all forms of representation, including language, should be regarded as dynamic processes of transformation rather than processes of reproduction (Cope \& Kalantzis, 2009). This type of pedagogy focuses on much broader modes of representation than language, 
which are differentiated according to culture and context and have specific cognitive, cultural and social influences (Cope \& Kalantzis, 2000, 2009, 2012, 2015). The purpose of multiliteracies is to develop students' critical language awareness and to enhance their communication and textual potential by exploiting their diverse cultural, social and textual experiences and background in the class (see also Archakis \& Tsakona, 2012).

Popular culture (e.g. television, films, comics) plays a central role in such an educational context, consequently it has been included in many school curricula (e.g. Alvermann et al., 1999; Stevens, 2001; Morrell, 2002). The recontextualization of popular culture in the classroom has been indicated to contribute to students' active participation in the learning process, as it is related to their actual social practices and experiences (Duff, 2004). Students' engagement with popular culture texts implies their practice in receptive and productive skills with clear communication purpose and sociolinguistic orientation, as linguistic diversity (e.g., geographic and social dialects) is also deemed necessary for the language course. Specifically, under the influence of sociolinguistics, it has been argued that an essential part of language teaching should be devoted to students' awareness raising regarding the dynamic and diverse nature of language, due to geographical, social, ethnic and stylistic factors, as well as to the development of their ability to creatively draw on this diversity for the achievement of their communicative and social purposes (see, in particular, Kakridis et al., 1999; Stamou, 2012). To this end, the teaching of popular culture can contribute to raising students' sociolinguistic awareness, as the discourse of popular culture is par excellence heteroglossic/polyphonic (see Coupland, 2009).

Complementing other literacy practices, multiliteracies pedagogy focuses on developing students' linguistic, sociolinguistic and digital literacy skills, so that students are active participants in social change, and become designers and constructors of the social future (Cope \& Kalantzis, 2000). According to Cope and Kalantzis (2009, pp. 167-168), teaching and learning about the design of meaning should include a combination of four stages: a) Situated Practice, which involves immersion in experience and the utilization of available designs (experiencing the new); b) Overt Instruction, which involves systematic, analytical, and conscious understanding, and requires the introduction of explicit metalanguage describing and interpreting the design elements of different modes of meaning (conceptualising with theory); c) Critical Framing, which means interpreting the social and cultural context, i.e., viewing the meanings critically in relation to their context (analysing critically); d)
Transformed Practice entailing transfer in meaningmaking practice (applying creatively) (see also Cope \& Kalantzis, 2015; Kalantzis \& Cope, 2012).

Taking into consideration the abovementioned model of the pedagogy of multiliteracies, we designed and implemented a longitudinal program sustained on a task-based framework aiming to develop young school children's critical awareness of linguistic diversity through popular culture texts in a collaborative, creative and multimodal educational environment. It was an interesting process for us to examine whether multiliteracies skills could be developed at an early age. Emphasis was placed not only on providing children with opportunities to get pleasure from the texts of popular culture, but also on developing their reflective stance towards those texts.

\section{Materials and Methods}

An attempt was made to design and implement a longitudinal program to young school children though four stages: experiencing, conceptualizing, analyzing and applying creatively, with the purpose to develop young children's critical awareness of linguistic diversity through popular culture texts in a collaborative, creative and multimodal educational environment, and ultimately, and enhance their multiliteracies skills. Moreover, an estimate of the efficacy of the program was attempted by using the following research tools: pre-test and post-test, the researcher's journal, portfolios and post interviews.

\section{Instruments and Data Analysis}

Pre-test and post-test. In order to identify a possible improvement in students' critical awareness of linguistic diversity through popular media texts in a collaborative, creative and multimodal educational environment, we explored how children actually decode media texts and how they conceptualize sociolinguistic diversity through those texts, before (pre-test) and after the implementation of the program (post-test).

Children's perspectives were explored through semi-structured individual interviews, which were conducted in a silent room at school. The children were shown some video clips from popular Greek TV series and films and were asked to comment on the sociolinguistically diverse speech styles of the characters. Those clips were chosen because they depicted characters speaking a range of different speech styles (e.g. Standard Modern Greek, Greek Northern rural accent, youth style of talk) (see Stamou et al., 2015). Each interview lasted about thirty 
minutes.

\section{The researcher's journal.}

The researcher kept a journal throughout the program, where he/she recorded and reflected on the events and experiences of each teaching intervention. In this way, a more detailed description of the program was made and an overall reflection on the entire process was recorded. The teacher-researcher used journals as a tool for formative evaluation by reflecting on her own work and interpreting it critically in order to refurbish it and improve it along the way (see Griva \& Kofou, 2018; Richards \& Lockhart, 1994).

Keeping notes and reflecting on them constitutes an ongoing process which helps the teacherresearcher to gather information and give feedback on the way the program works, so that he/she can make improvements, where needed, as regards to methods, materials, teaching processes and students' learning 'paths' (Griva \& Kofou, 2018).

\section{Portfolios.}

Every group used a portfolio as a collection of their work demonstrating achievement or improvement. Portfolios were considered a formative and processoriented tool for documenting and reporting learning outcomes on a continuous basis (see Griva \& Kofou, 2018; Stiggins, 1994). Children's collection of works comprised the results of the activities and games carried out in the main and post-stage of the program; such as written work on sociolinguistic aspects, notes, language games, drawings, creations and role-play games.

The children, in collaboration with the teacher, reflected on and articulated their thinking about each piece of work. When assessing children's work related to the role play games, the researchers checked the transcribed linguistic scripts and dialogues created by the children on the basis of topical appropriateness, creativity and fluency. In relation to the analysis of drawings and paintings, the researchers considered the way in which the characters of the videos were depicted by the children (e.g. color selection, selection and size of objects, accompanying linguistic scripts, etc.).

\section{Post interviews}

Upon the completion of the intervention, the researchers conducted structured interviews with the children to identify the knowledge they had acquired in the specific educational context, but also to record what they liked the most. The researchers encouraged children to feel free to answer the following age- appropriate questions:

What did you like most about the program?

- What was it that made you encounter difficulties during the program?

- What do you think could be done in a different way?

- What did you learn best?

- Would you like to participate in similar types of activities next year?

\section{General Background of Research}

\section{The program: 'Learning about linguistic diversity} on TV'. Before initiating the design of the program, we identified young children's preferences for popular culture, and in particular their preferences for television programs (such as cartoons and TV series) (Stamou et al., 2014), and we mapped teachers' views on the use of popular culture at school (Maroniti \& Stamou, 2014). Moreover, through semi-structured interviews, we explored children's perspectives while commenting on the sociolinguistically diverse speech styles of the characters watched in some video clips (animated films, popular Greek TV series) (Stamou et al., 2015).

Based on the collected data, we designed educational materials composed of selected TV commercials and videos from popular Greek TV serials, with content appropriate to the children's age $(M$. age $=7.5)$, which emphasized the sociolinguistically diverse speech of the characters speaking a range of different styles (see also Maroniti et al., 2015). The purpose was to develop students' critical awareness of television phenomena representing sociolinguistic diversity in an interactive, collaborative, creative and multimodal educational environment. The development of a critical stance is considered necessary, as it has been indicated that television and film tend to represent linguistic diversity in a way that the dominant language ideologies of homogenization are reproduced, e.g. through the allocation of low-status speech styles to peripheral and low-class characters, whereas sociallyprestigious speech styles are usually employed for the construction of central and elite characters' speech (Stamou, 2014; in press).

\section{Materials.}

The units were delivered in a multimodal environment comprising educational videos of popular TV series, maps, posters and pictures, in an attempt to raise the students' critical awareness to empower 
their communicative behavior and multiliteracies skills. The modules were also delivered in a task-based context, which presented the students with a variety of games and playful activities, including on-line games, designing posters, working on arts and crafts, doing puzzles, taking part in role-playing, doing pantomime, learning new songs, delivering presentations, and participating in debates among others. These activities provided the students with a rich experience of real language used in different social contexts, stimulated their curiosity, challenged them to engage actively and develop their creativity, free expression as well as their interactional skills (Griva \& Chostelidou, 2017; Griva \& Semoglou, 2012).

It is widely accepted that games and role playing are activities that provide children with opportunities to practice various language aspects assuming a role, or by drawing on the newly required knowledge and applying it creatively in new contexts (see Aldavero, 2008). In this vein, playing is a significant way to develop critical language awareness focusing on children's participation and enjoyment in a relaxed situation (Dryden \& Vos, 2001), as well as to interact with other peers in a pleasurable 'low risk' context (Tomlinson \& Masuhara, 2009).

The program was designed around twelve units per school year, aiming to promote children's critical language awareness, with each unit lasting 3 hours. Three units, one for each type of linguistic diversity (geographical, age, social class), were selected for the purpose of this study (see section 3):

- Learning about dialects (see Unit related to geographic diversity).

- Learning about youth speech styles (see Unit related to age diversity).

- Learning about social class linguistic differences (see Unit related to the social class diversity).

\section{Participants}

The sample consisted of 41 young children (20 boys and 21 girls), 20 first graders and 21 second graders of a Greek experimental primary school supervised by the University of Western Macedonia. Our basic aim was to implement the experiment with students of the school which was affiliated with our University. All children came from the same geographical area, Florina city, a small city in north-western Greece, and were exposed to the same language. Greek was their only L1 (first language), as there were on migrant children in the group.

The longitudinal program was carried out for two school years: a) In the first school year, an intervention was implemented to children of the $2^{\text {nd }}$ grade, and b) in the second school year, a similar intervention was applied to children of the $1^{\text {st }}$ grade (see also Maroniti et al., 2016)

\section{Research design}

Task-based framework for developing multiliteracies skills.

The program was carried out in a task-based framework, following the four-stage multiliteracies model of Cope \& Kalantzis (2000), as sketched above. In particular, in the 'task-based' context (Willis, 1996), students get engaged in problem-solving activities and try to find solutions through co-operation, interaction and co-decision. In such an educational context, according to Porter-Ladousse (1987) and Jacobs (1988), students are given the opportunity to activate their prior knowledge, stimulate their participation in inquiry-based activities, as well as to get involved in authentic communication within the classroom and express their creativity (Griva \& Semoglou, 2015).

In the present paper, an attempt was made to help children learn by:

a) being with others, while feeling secure and confident enough to take risks, to explore, and to take part in challenging experiences (Broady, 2006; Johnson \& Johnson, 1999);

b) experiencing, analyzing, making choices and decisions, solving problems, and developing critical language awareness.

Special attention was drawn to the playful and creative activities that were implemented by the teacher and the techniques also used such as brainstorming, creative writing activities, physical activities, board games. It is worth mentioning that the teacher served as a facilitator of the students' development throughout the program, by encouraging their participation and interaction.

\section{Pre-stage: Experiencing.}

The purpose of the 'pre-stage' (corresponding to the 'situated practice' of Cope \& Kalantzis, 2000) was to activate students' prior knowledge, introduce them to the topic, and make them experience new knowledge about television phenomena representing sociolinguistic diversity in an interactive, creative and multimodal environment (e.g. ppt, prezzi, video clips, songs, pictures, questions and answers etc.).

\section{Task-cycle: Conceptualizing and analyzing.}

The purpose of the 'task-cycle' (corresponding to the 'overt instruction' and 'critical framing' of Cope 
\& Kazantzis, 2000) was: a) to prepare the children to understand the linguistic and textual mechanisms of the popular culture texts and interpret the texts with the teacher's guidance; b) to make them identify and reflect critically on the stereotypes that concern the television representations of linguistic diversity.

Initially, the children were familiarized with various mechanisms of stigmatization of linguistic diversity, for example, of stress and intonation pronunciation. While discussing with the teacher and interacting with classmates within each group, they were able to trace these mechanisms and gradually develop critical awareness of the ways sociolinguistic diversity is portrayed on TV.

The activities included at this stage were related to watching a TV video clip, participating in critical discussions about the topic of the video, painting and designing, completing vocabulary games etc. The students cooperated on a common group task, interacting with each other during "problemsolving negotiation" and assuming responsibility for contributing to the group task. Emphasis was placed on interpersonal relationships and group dynamics, by providing children with opportunities and encouraging them to participate actively in the learning process with the purpose of achieving efficient learning outcomes. The teacher was the coordinator and experienced member of the group, who encouraged children to explain or describe these displays to their classmates (see also Vrinioti \& Griva, 2015). Upon the completion of the task, the leader of each group announced their decision and presented the process of solving the problem and their 'product' to the teacher and the classmates.

\section{Post-stage: Applying creatively.}

The purpose of the 'post-stage' (corresponding to the 'transformed practice' of Cope \& Kazantzis, 2000) was to make children apply appropriately and creatively new knowledge about sociolinguistic diversity acquired in the task-cycle stage, through participation in cooperative activities and role play games. As this stage entailed transfer in meaningmaking practice (see Cope and Kalantzis, 2009), the children, through being engaged into multimodalmultisensory activities of critical linguistic awareness, applied creatively newly acquired knowledge into other contexts. In other words, they were asked to recreate and re-contextualize new knowledge through their participation in playful and creative activities, such as games, role play and pantomime.

For the purpose of the program, we divided the children into four groups of four to five members each, so that all children could have the opportunity to work collaboratively. The researcher-teacher asked the children to choose a representative name for each group, and they chose to use names from their favorite cartoon heroes, which is another sign of their strong involvement in popular culture. The first group chose 'SpongeBob', the second group 'Goofy', the third group 'Bugs Bunny' and the fourth one 'Taz'.

\section{Procedure}

Indicative Learning Units. Unit: Learning about dialects. Pre-stage: Experiencing. The objective of this stage was to bring children into contact with different speech styles used by people in diverse geographical areas and to make them identify/ understand how speech is often different among people coming from different areas of the country.

Activity: Children were presented with a map of Greece and Cyprus, while listening to some traditional dialectal songs representative of various Greekspeaking regions (e.g. Corfu, Thrace, Crete, Macedonia, and Cyprus) in a multimodal environment.

Procedure: The children were encouraged to initiate a discussion in plenary, based on some of the following questions.

- Did you notice anything strange in the singer's way of speaking?

- Have you ever heard someone speak in this way? Where?

- Which speech style do you like most? Why?

\section{Task-cycle: Conceptualizing and analysing.}

The basic objective of this stage was to make children realize that the TV portrayal of geographic diversity is associated with specific (mostly negative) social characteristics and different dressing code.

\section{Main Task}

Video watching: (http://www.youtube.com/ watch?v=7VRIcAejN3o) 'The Corfiot mother-in-law'.

This episode is part of the famous TV comedy series Seven Thanasimes Petheres (Seven Deadly Mothers-inLaw) which was broadcast in Greece from 2004 until 2010. The TV series depicts different types of mothersin-law, often using different geographical dialect or sociolect and they also tend to represent them as vicious or naïve, always trying to interfere in their children's life. In this episode, the Corfiot mother-inlaw, Aghiolina, is a middle-aged woman from Corfu, who speaks the Corfiot dialect.

First activity: Reflect critically on the video extract. After watching the video, the teacher assigned the groups some questions to reflect on, to discuss, and provide answers to them. Every group had to select a question/topic to work on: 
- Did you notice any difference in the way the characters speak? Were there any words that you did not understand? Why do you think this happened?

- How is Aghiolina presented, and how are her brides? Who do you like most? Why;

- Do you think you could come across a Corfiot like Aghiolina? Could he/she speak differently?

- If Aghiolina met you, would she speak in this way, despite the fact that you speak differently from her? What do you think?

Second activity: Distinguish between standard and dialectal speech styles. The teacher split the class into groups of four children, and gave them some phrases of 'standard language' and 'Corfiot variety' on small pieces of paper (for example: Ti einai ore pali, ego sou to exo pei na pareis dio-tria garsonia gia na mporoume na vgainoume, sygxarikia, tsi tsoupres mou, mporei na thelei na paraggelei kati allo, niorantisses, do mou to piato sou...). Then she asked the students to stick them on a cardboard in two columns, the "Corfiot variety" and the "standard language". Some of those phrases/ words were heard in the media text and some of them came from other episodes of the TV series (see Picture 1).
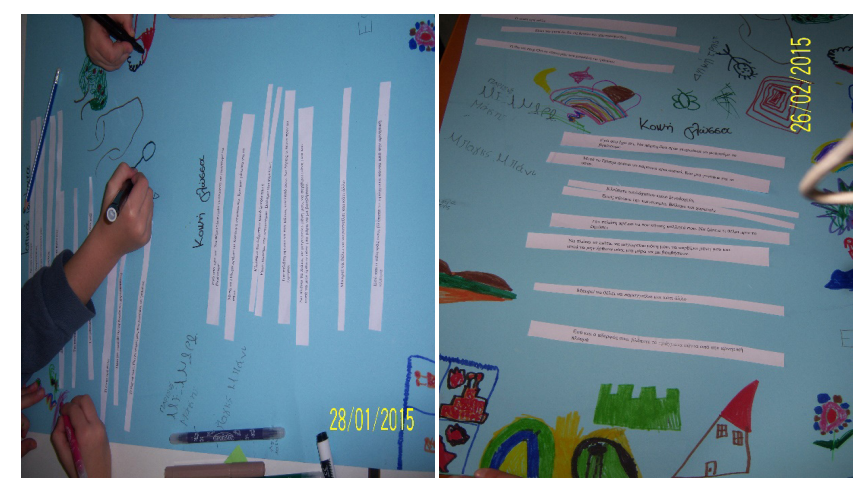

Picture 1. Matching captions of the "Corfiot variety" with the "Standard language".

Post-stage: Applying creatively. The main objective of this stage was to make children apply appropriately and creatively the newly acquired knowledge on geographic diversity and transform it critically to a new context.

Activity: Relay and role playing. The teacher put the students into groups and engaged them in playing relay with words/ phrases from various dialects. She then placed two baskets in front of each group, one corresponding to the standard language and the other to the dialects. Whenever a sound extract from a dialect or the standard language was heard, the child had to decide on which basket he/she would put his/ her card into.

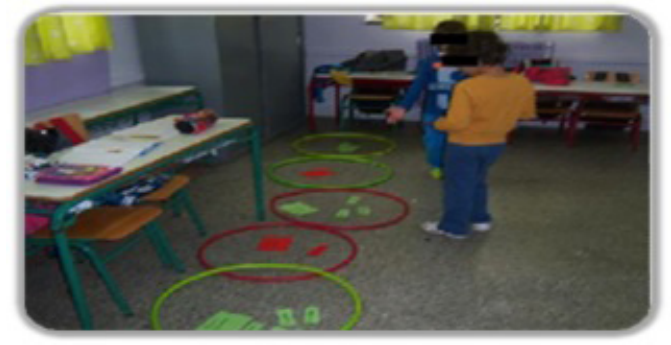

Picture 2. Children get prepared to participate in relay.

The children were then asked to participate in a role play game: "a new student, Spyros from Corfu, has just come to school. The children are invited to help him to meet his new friends and describe his favorite Corfiot food". The children were free to choose whether to use the geographical dialect or just the standard variety from a list of phrases provided in both language codes (Picture 3).

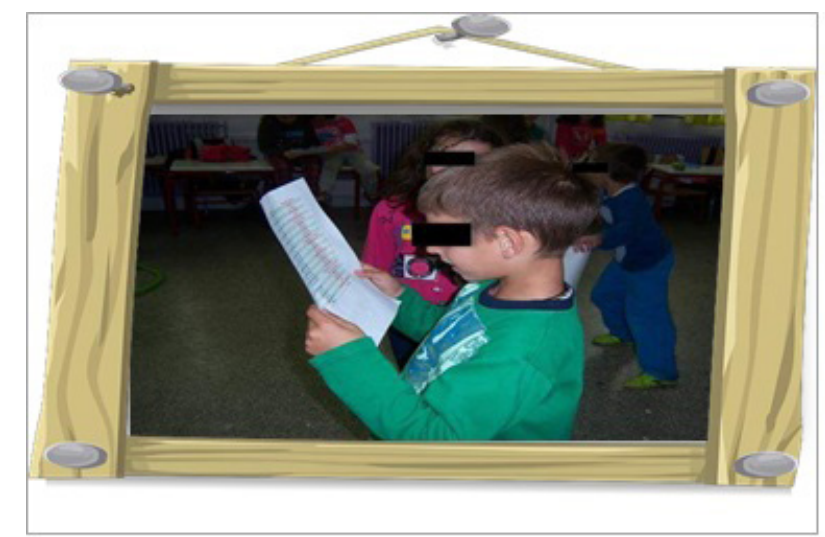

Picture 3. Children are participating in the role play.

\section{Unit: Learning about youth speech styles.}

Pre-stage: Experiencing. The objective of this stage was to bring children into contact with different speech styles used by people of different ages and to make them identify/understand how youth speech styles may differ from adults. In addition, an attempt was made to make children realize that the representation of youth speech styles on TV is portrayed as a single and homogeneous sociolect (a 'youth language'), while reproducing rather negative stereotypes of young people related to laxity, immaturity, familiarity with technology, engagement in unconventional youth cultures (see also Saltidou \& Stamou, 2014).

Activity: The children watched the following TV commercials (Molto, OTE, Germanos) with young people using 'youth language' and adult people who do not understand it, as well as TV commercials in which young people become part of unconventional youth cultures. 
- http://www.youtube.com/watch?v=-LxXNihoNdM (Molto TV commercial).

- http://www.youtube.com/watch?v=-6or7G30shY (OTE TV commercial).

- http://www.youtube.com/watch?v=fEWJ9eeqwco (Germanos TV commercial).

- http://www.youtube.com/watch?v=_UUFLvVAhLI (Molto TV commercial 2).

Procedure: The children were encouraged to initiate a discussion on some of the following questions.

- Have you noticed any difference in the way young people talk?

- Do you understand what young people say in the commercial?

- Did you notice any communication problems between young people and adults?

Task-cycle: Conceptualizing and analysing. The purpose of this stage was to make children understand the television reproduction of negative stereotypes of young people. Young people and their styles of talk are associated with negative stereotypes, such as laxity, immaturity, superficiality, or cunning behavior. Moreover, the 'gap' of perceptions and worldview between youth and adulthood is highlighted by the adults who are presented to express their views on the socially 'correct' way of talking and behaving.

Main Task. Video watching: Reflection on young people's and adults' styles of talk

The children watched three clips from the famous Greek TV series Deka Lepta Kirigma (Ten-Minute Preaching), which was broadcast from 2000 until 2004. The plot revolves around the 'preaching' that the teenage protagonist Leonidas is subjected to by his mother, Mary, and to a lesser extent by his grandmother, Kikitsa, or his mother's friend and colleague, Zeta, in order to conform to the adults' model of the 'good child'. Leonidas, along with his friends Telis and Marilena, have a keen interest in hip-hop music and culture, but they are completely indifferent to school:

- http://www.youtube.com/watch?v=mefYZKnrQM (Leonidas-Telis-Kikitsa-Mary-, episode: 1, 36.13'-37.55');

- http://www.youtube.com/watch?v=2_8GR3LuLG4 (Leonidas-Kikitsa-Mary/ episode: 2, 18.03'20.14').

- http://www.youtube.com/watch?v=ydT1IaKiGtg (Leonidas-Kikitsa-Mary-Zeta/ episode: 3, 14.50'$\left.16.48^{\prime}\right)$.

The teacher discussed with the children the young people's (Telis and Leonidas) style of talk, which expresses their emotional status, their age and interests, and which is negatively commented on by adults. The teacher posed the following questions: "Could it be otherwise?"; "Could an elderly person (such as Leonidas's grandmother Kikitsa) speak and behave like Leonidas (a young person)?”.

\section{First activity: Reflect critically on the video clip}

Then, the teacher assigned the groups some questions to reflect on, to discuss, and provide answers to them. Every group had to select a question/topic to work on:

- Did you notice any communication issues between the characters of different age (Leonidas-Kikitsa-Mary)? Why do you think this happened?

- How are Leonidas and Telis presented in relation to their character, behavior and their aspirations / dreams?

- Why does Leonidas believe that there is a gap between young people's views and adult ones?

\section{Second activity: Analyze critically}

Match words and expressions of youth speech style and standard variety to the character's photography.

Children cooperated in groups, helping each other, interacting with each other, and assuming responsibility for contributing to the group task. Each group was provided with photos of the four characters (Leonidas, Telis, Kikitsa, Mary), as well as some words/expressions of youth style of talk and the standard variety that had been heard in the clips of the series. Then, the children were asked to match the words or expressions to the right character, on a large cardboard. Upon the completion of the task, the leader of each group announced their decision and presented the creations to the teacher and the classmates.

\section{Post-stage: Applying creatively.}

The objective of this stage was to make children apply appropriately and creatively the newly acquired knowledge of the speech style related to the age.

Activity: Create a mask in relation to the characters of the episodes of the series and participate in a role play.

The teacher put the students into groups and asked them to collaborate and create the masks and present them in the plenary. In the next step, the children were asked to get engaged in a role play: to present a conversation between an elderly man (e.g. grandmother or grandfather with her / his grandson /daughter about the summer holiday). The children were free to choose either the words and expressions used by young people or those used by elderly persons in the previous activity. 
Unit: Learning about linguistic differences: Social classes.

Pre-stage: Experiencing The objective of this stage was to bring children into contact with different speech styles used by people of different socio-economic backgrounds and to make them identify/ understand the way speech is often different between people of high status professions and those of low status.

Activity: The students were presented with some TV commercials including a speaker of low-status speech style.

- https://www.youtube.com/watch?v=i_9MMu_ yShM

- https://www.youtube.com/watch?v=lvEAF_ Eqwek

Procedure: The children were encouraged to initiate a discussion on the following questions:

- What do you think of the man's speech style? Do you notice anything different from the way you speak?

- Have you heard anybody else talking like that? When?

- Do you think the way he is dressed suits the way he talks? Why?

Task-cycle: Conceptualizing and analysing. The main objective of this stage was to make children realize that every social class is portrayed on television in a humorous and stereotypical way, giving the impression that the social classes are in sharp contrast. Also, their representation on TV is related to both positive and negative social stereotypes.

Main Task. Video watching: Reflect critically on the video clip A clip (episode: 1, 10:40'-14:23') from the TV series Men kai Den (The Ones and The Others) was shown (http://www.youtube.com/watch?v=CYEFCzXTGaI) to the children. It was a comedy TV series which was broadcast in Greece in 1993-1996. The plot is based on two families from a distinct socio-economic background: the Daga family and the Stamati family. The Dagas are represented as an upper-class, rich and well-educated family, who use highly prestigious standardized language forms. In contrast, the Stamatis are represented as a loudly, cunning, lazy and loweducated family, who employ stigmatized nonstandard speech styles (e.g. street language, youth style of talk).
First Activity: Critical discussion and reflection on high- and low-status speech styles.

After watching the clip, the teacher assigned the groups some questions to reflect on, to discuss and provide answers to them. Every group had to select a question/topic to work on:

- Did you notice any difference in the way the characters speak? Does one family understand the other? Why; who would you like to be friends with? Why?

- How do those people who speak the low-status speech style look like?

- How do those people who speak the high-status speech style look like? Do you think people differ so much in real life? Why?

Second activity: Design the house of your favorite character

The teacher put the students into groups and asked the members of each group to choose and create the house they prefer, either the Daga family's house or that of the Stamati family (Pictures 4 and 5). Upon the completion of the task, the leader of each group presented their construction and explained their choice to the teacher and the classmates.
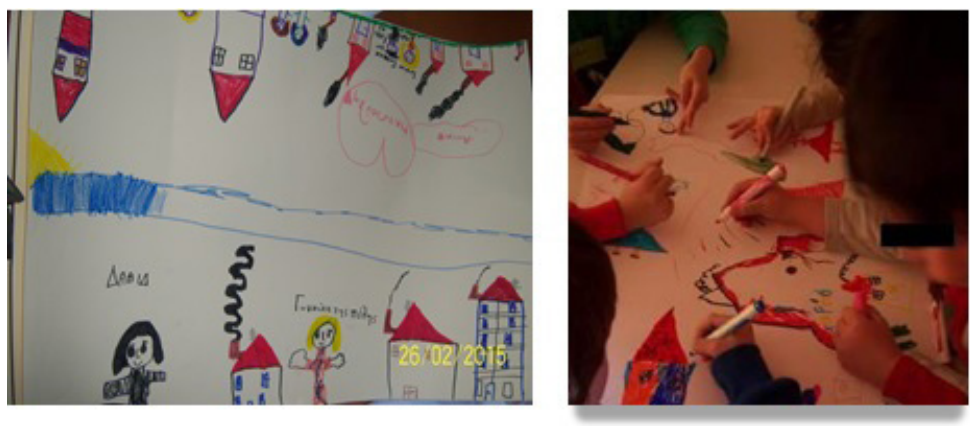

Pictures 4 and 5. The children are creating the houses of the two families.

Post-stage: Applying creatively. The objective of this stage was to help children apply functionally and creatively the acquired knowledge and transform it critically to a new context.

Activity: Board game and role play

All groups were in front of a large board game consisting of numbered squares (see Pictures 6 and 7). Depending on the roll that each group would bring, they opened the corresponding box where there was a 'hidden' order. 

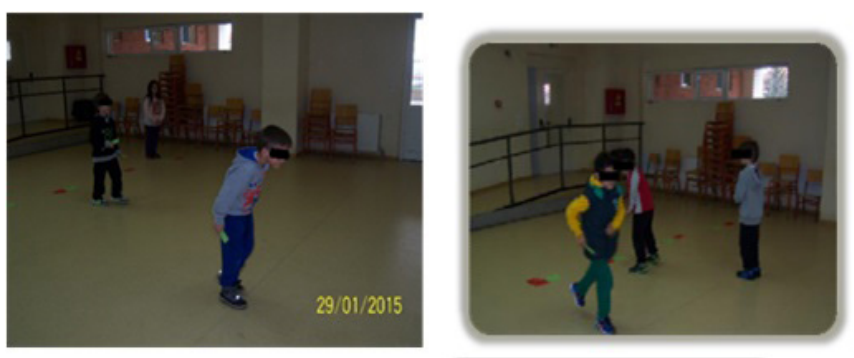

Pictures 6 and 7. Children are participating in the game.

The orders contained some helpful questions so that the children could easily perform them (see Pictures 8 and 9). For example, some of the orders may be: "the Daga family goes to the doctor" (how do they speak to the doctor? will they be polite? will they cry out?), "The Danga family are supermarket employees" (how do they behave? How do they speak?), "The Stamati family are customers in a clothes store" (how will they speak? Will they be polite? Will they be arrogant?). The children should reflect critically on these questions based on the newly acquired knowledge.
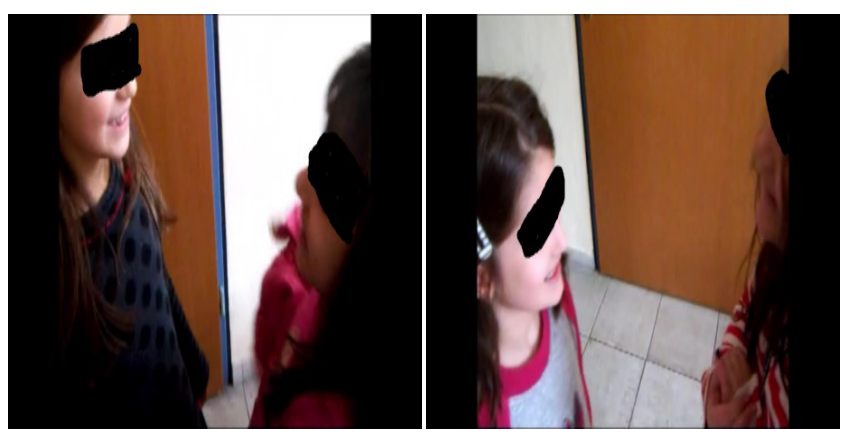

Pictures 8 and 9. Children are participating in the role play game.

\section{Results}

From the thematic analysis of children's pre-test, it was found that they can easily distinguish between different dimensions of sociolinguistic difference, showing an enhanced sociolinguistic awareness. Moreover, we found a general convergence of the children with the common/usual "reading" approach of television representations, where linguistic heterogeneity tends to be "stigmatized" and used for humorous purposes (e.g. Stamou, 2011). Some children noticed that a different speech style may cause laughter. There were also children who declared they felt sorry for a particular character, because he "speaks badly". Thus, most children tended to express "negative" or "indifferent" feelings towards nonstandard varieties and did not accept the characters that spoke these varieties. In other words, their perceptions proved to be in line with traditional language stereotypes.

For example, when the children watched a video from the Greek TV series, Constantine and Helen, where Constantine's speech style was marked standard Modern Greek and Helen's was marked non-standard Modern Greek, most of the children responded that they could distinguish between the speech styles of Constantine and Helen (Table 1). Nevertheless, they appeared divided regarding their feelings (with negative feelings, though, slightly dominating positive ones) towards both the marked Standard Modern Greek of Constantine and the marked nonstandard Modern Greek of Helen. Equally ambivalent were children's responses with respect to the social attractiveness of both characters. The negative evaluation of Constantine's marked standard was justified through unintelligibility (e.g. "he speaks differently and I don't understand him", "he uses words that I don't understand", "he uses long and difficult words", "he uses weird words") and seriousness (e.g. "he speaks seriously", "he speaks sternly", "his words are bad"), while children's negative comments on Helen's marked nonstandard were justified through aesthetics (e.g. "she does not use nice words", "she does not speak nicely", "she uses ugly words", "she uses bad words") and otherness (e.g. "she speaks a bit weirdly", "she speaks differently") (see also Stamou, Maroniti, \& Griva, 2015).

Similar results were revealed in children's works collected in the portfolios. In particular, the researchers identified masks designed by the children that expressed feelings of wonder or even anger about youth speech styles, as well as some other pieces of work that expressed feelings of laughter or joy towards this type of linguistic diversity. On the contrary, the analysis of the children's pieces of work relating to geographical diversity showed that the majority of them completed the activity unproblematically, proving that children of this age have developed some sociolinguistic awareness of dialectal diversity.

Since the program aimed at helping children understand and become aware of the ideological role of television representations of linguistic diversity and, therefore, to 'reject' stereotypes of nonstandard speech styles, during the post-test, we expected children to express more positive feelings towards the characters of "divergent" linguistic behavior. However, there were no significant differences between pre-and post-test, a fact that may be attributed to certain issues and difficulties having arisen during the 'applying creatively' stage, but also to the constraints imposed by the 'measurement' of qualitative data such as the development of critical sociolinguistic awareness. 
Table 1

Categories and subcategories of the thematic strand "Children's views on social variation of social class"

\begin{tabular}{|c|c|c|c|c|}
\hline & Categories & Sub-categories & $\begin{array}{c}\text { Pre-test } \\
\text { Occurrences }\end{array}$ & $\begin{array}{l}\text { Post-test } \\
\text { Occurrences }\end{array}$ \\
\hline \multirow{2}{*}{1.} & \multirow{2}{*}{$\begin{array}{l}\text { Feelings towards Helen's marked } \\
\text { non-standard modern Greek }\end{array}$} & Positive feelings towards Helen's marked non-standard & 13 & 21 \\
\hline & & Negative feelings towards Helen's marked non-standard & 28 & 20 \\
\hline \multirow{2}{*}{2.} & \multirow{2}{*}{$\begin{array}{l}\text { Feelings towards Constantine's } \\
\text { marked standard modern Greek }\end{array}$} & Positive feelings towards Constantine's marked standard & 25 & 23 \\
\hline & & Negative feelings towards Constantine's marked standard & 16 & 18 \\
\hline \multirow{2}{*}{3.} & \multirow{2}{*}{$\begin{array}{l}\text { Awareness of the differences } \\
\text { between Constantine's marked } \\
\text { standard modern Greek and } \\
\text { Helen's marked non-standard }\end{array}$} & $\begin{array}{l}\text { Ability to distinguish between Constantine's marked } \\
\text { standard and Helen's marked non-standard }\end{array}$ & 19 & 32 \\
\hline & & $\begin{array}{l}\text { Inability to distinguish between Constantine's marked } \\
\text { standard and Helen's marked non-standard }\end{array}$ & 22 & 9 \\
\hline \multirow{3}{*}{4.} & \multirow{3}{*}{$\begin{array}{l}\text { Preference for Constantine's } \\
\text { marked standard or Helen's } \\
\text { marked non-standard }\end{array}$} & $\begin{array}{l}\text { Preference for Constantine's marked standard in relation to } \\
\text { Helen's marked non-standard }\end{array}$ & 20 & 22 \\
\hline & & $\begin{array}{l}\text { Preference for Helen's marked non-standard in relation to } \\
\text { Constantine's marked standard }\end{array}$ & 14 & 19 \\
\hline & & $\begin{array}{l}\text { No preference for Constantine's marked standard or } \\
\text { Helen's marked non-standard }\end{array}$ & 7 & - \\
\hline \multirow{4}{*}{5.} & \multirow{4}{*}{$\begin{array}{l}\begin{array}{l}\text { Evaluation of the } \begin{array}{r}\text { social } \\
\text { attractiveness } \\
\text { between }\end{array} \\
\text { Constantine and Helen }\end{array}\end{array}$} & Positive feelings towards Constantine as a character & 11 & 12 \\
\hline & & Positive feelings towards Helen as a character & 22 & 21 \\
\hline & & $\begin{array}{l}\text { Positive feelings towards both Constantine and Helen as } \\
\text { characters }\end{array}$ & 6 & 7 \\
\hline & & $\begin{array}{l}\text { Positive feelings towards neither Constantine nor Helen as } \\
\text { characters }\end{array}$ & 2 & 1 \\
\hline \multirow{2}{*}{6.} & \multirow{2}{*}{$\begin{array}{l}\text { Preference for using Constantine's } \\
\text { and Helen's speech styles }\end{array}$} & Preference for talking like Constantine to Helen & 31 & 28 \\
\hline & & Preference for talking like Helen to Constantine & 10 & 13 \\
\hline
\end{tabular}

The qualitative analysis of the data of the researcher's journal revealed that the majority of the educational objectives were fulfilled to a significant degree. It was found that children at seven years old possess an enhanced critical awareness, as they exhibited a good ability to distinguish between different dimensions of sociolinguistic diversity (see Table 2). Besides, they were also able to realize that, on TV, this diversity is not only depicted through speech, but also through visuals (e.g. appearance, dressing, home decoration), considerably enhancing their multiliteracies skills. Moreover, the program implementation led to the development of the students' critical awareness, allowing them to understand the 'gap' between television representations of linguistic diversity and their own sociolinguistic experience (see Table 2).

Having said that, it was also revealed that some difficulties arose, especially at the stage of "transformed practice", where children in many cases tended to reproduce the stereotyped television imagery of linguistic diversity, instead of transforming creatively the newly acquired knowledge. This resulted into their inability to critically transfer the acquired knowledge to a new context, maybe because they are in their early childhood years. Moreover, the teacher's guidance limited children's expression in re-contextualizing "newly acquired" knowledge. As a consequence, they produced more or less conventional texts without approaching linguistic diversity creatively and critically.

Despite the problems that have arisen, the qualitative analysis of the children's post interview data indicated a generally positive attitude towards the program. The great majority of the children declared they did not encounter any difficulty during the program, while two of them mentioned they faced some difficulties in discussing about the video on the pre-stage, but they were not able to identify and describe the exact issues. It is very encouraging that 
Table 2

Typologies, categories and subcategories of journal entries

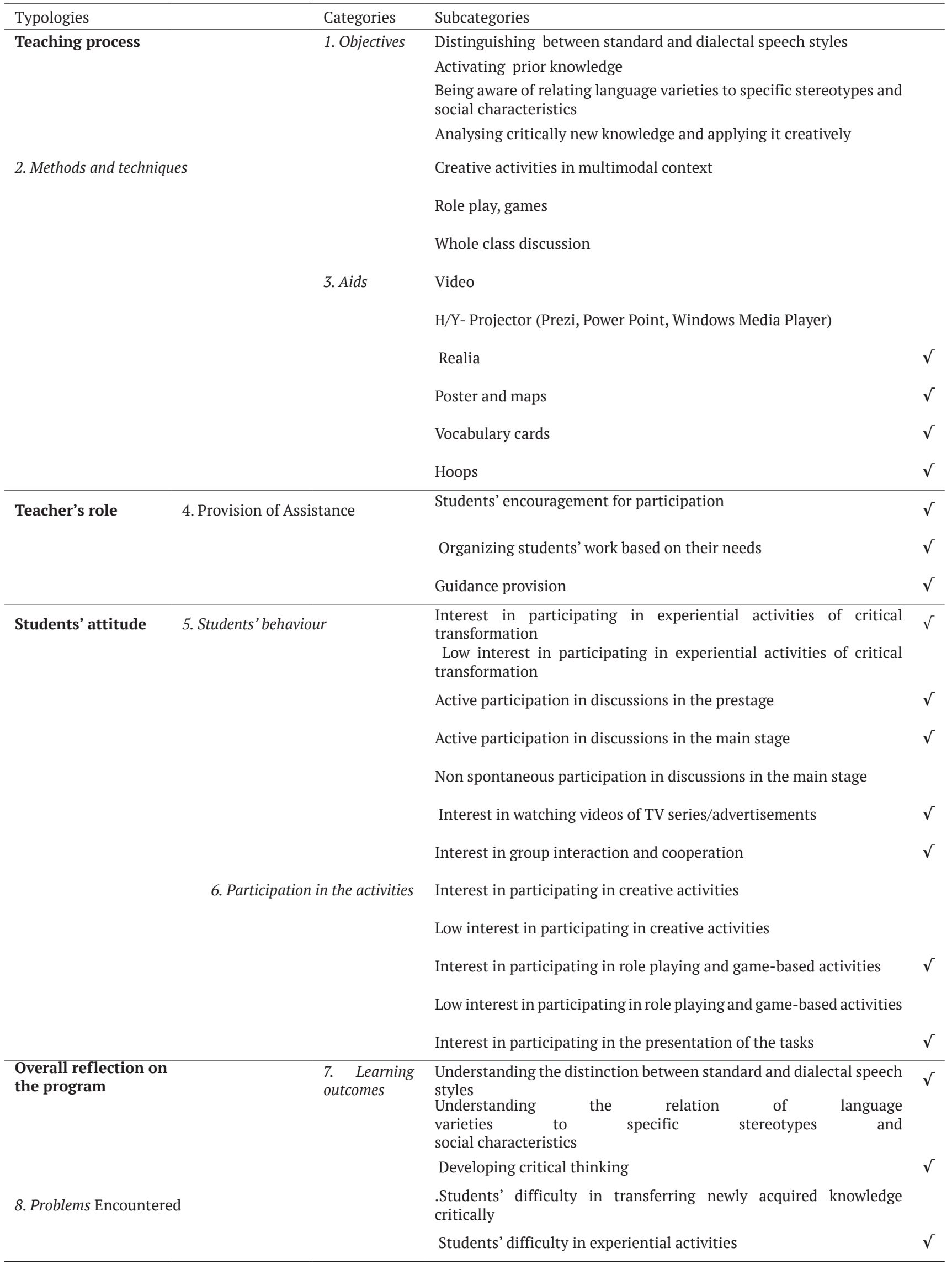


the children showed great interest in actively and enthusiastically being involved in most activities and games, such as vocabulary games, creating paintings and watching video clips. Representative results are shown in Table 3.

Table 3

Results of the children's post interviews

\begin{tabular}{|c|c|}
\hline 1. Children's preference for activities & Occurrences \\
\hline 1.1 Vocabulary games & 36 \\
\hline 1.2 Drawing & 35 \\
\hline 1.3 Watching TV videos & 35 \\
\hline 1.4 Role playing & 33 \\
\hline 1.5 physical activities & 22 \\
\hline \multicolumn{2}{|l|}{ 2. Knowledge acquisition } \\
\hline 2.1 Awareness of sociolinguistic diversity & 35 \\
\hline 2.2 Awareness of language attitudes & 13 \\
\hline \multicolumn{2}{|l|}{ 3. Difficulties encountered } \\
\hline 3.1 No difficulties & 29 \\
\hline $\begin{array}{l}\text { 3.2 Difficulties in participating in whole } \\
\text { classroom discussion }\end{array}$ & 12 \\
\hline \multicolumn{2}{|l|}{ 4. Participation in the project in the next grade } \\
\hline 4.1 Desire to participate in the project once again & 38 \\
\hline 4.2 Unwillingness to participate & 3 \\
\hline
\end{tabular}

This demonstrates that the participants' engagement into multimodal resources being at the core of their interests, such as popular culture, as well as their spontaneous participation in interactive, playful and multisensory classroom environment cultivated positive feelings about nonstandard varieties.

\section{Conclusion}

In this paper, we presented a longitudinal program designed and implemented to young school children though four stages: experiencing, conceptualizing, analyzing and applying creatively, with the purpose of developing children's critical awareness of linguistic diversity through popular culture texts in a collaborative, creative and multimodal educational environment, and ultimately, enhancing their multiliteracies skills. A generic analysis of the results suggests that the program had a positive impact of the program on children's ability to easily distinguish among different types of speech styles due to geographical, age and socio-economic factors, although the pre-test data indicated that children had already had a certain degree of sociolinguistic awareness. More importantly, through their participation in the program, the children were able to realize that the diverse speech styles as television representations tend to be constructed as causing barriers to communication and comprehension. In this way, they showed a higher degree of understanding of the discrepancy between the TV characters and their own sociolinguistic experience through the critical discussion on specific patterns of television discourse.

Another point to consider is that such an intervention promotes a different educational culture which impinges on the existing curriculum provision and the existing structures in Greek education, as well as on the established beliefs and perceptions of both teachers and students on issues related to conceptualizing language and adopting certain teaching approaches in the language classroom (Koutsogiannis, 2006). In addition, parents seem to have some reservations about using popular cultural texts in their children's classrooms, which means that there is a need for close collaboration between school and family for the effectiveness of the implementation of such a program (Stamou et al., 2014).

Sociolinguistic stereotypes tend to be particularly "resistant" even from an early age, as they are wellestablished perceptions that are difficult to change entirely. However, through the implementation of the longitudinal program of critical language awareness, which followed the multiliteracies model (see Cope \& Kalatzis, 2000; Kalatzis \& Cope, 2012) in a task-based framework, it was revealed that children understood - at least to some extent - that the texts of popular culture tend to display language diversity in a distorted and stigmatized way, by reproducing dominant perceptions and beliefs about language and the world.

In conclusion, the results of the implementation into two classes were very encouraging; a fact that stimulates our interest in continuing respective ventures (Maroniti et al., 2016). Thus, the program should be continued in the future, on a more systematic basis, involving a wider sample of students and teachers, as well as incorporating a great range of popular culture texts, aiming at reversing established beliefs about sociolinguistic reality. Launching such a project on a wider scale and for a longer time could possibly contribute to further developing children's multiliteracies skills, sensitizing them even deeper on diversity issues, and enhancing their ability to easily distinguish between different types of speech styles. 


\section{References}

Aldavero, V. A. (2008). Drama in the development of oral spontaneous communication. Encuentro, 17, 40-43.

Alvermann, D., Moon, J., \& Hagood, M. (1999). Popular culture in the classroom. Newark, DE; Chicago, IL: International Reading Association and the National Reading Conference.

Archakis, A., \& Tsakona, V. (2012). The narrative construction of identities in critical education. Basingstoke, UK: Palgrave Macmillan.

Broady, E. (2006) Learning and interaction: Developing through talk. Language Learning Journal, 34, 62-66.

Cope, B., \& Kalantzis, M. (1993). The powers of literacy: A genre approach to teaching writing. London, UK: The Falmer Press.

Cope, B., \& Kalantzis, M. (2000). Multiliteracies: Literacy learning and the design of social futures. London, UK: Routledge.

Cope, B., \& Kalantzis, M. (2009). Mutliliteracies: New literacies, new learning, Pedagogies: $A n$ International Journal, 4, 164-195.

Cope, B. \& Kalantzis, M. (2012). Multiliteracies in education. In The Encyclopedia of Applied Linguistics. Hoboken, NJ: Wiley Blackwell.

Cope, B. \& Kalantzis, M. (2015). The things you do to know: An introduction to the pedagogy of multiliteracies. In B. Cope \& M. Kalantzis (Eds.), A Pedagogy of Multiliteracies. Learning by Design (pp. 1-37). New York, NY: Palgrave Macmillan.

Coupland, N. (2009). The mediated performance of vernaculars. Journal of English Linguistics, 37, 284300.

Dryden, G., \& Vos, J. (2001). The learning revolution. Stafford, UK: Network Educational Press.

Duff, P. A. (2004). Intertextuality and hybrid discourses: The infusion of pop culture in educational discourse. Linguistics \& Education, 14, 231-276.

Griva, E., \& Semoglou, K. (2012). Estimating the effectiveness and feasibility of an early EFL learning project based on physical activities. English Language Teaching, 5(9), 33-44.

Griva, E., \& Semoglou, K. (2015). Foreign language and games: Designing and implementing creative physical activities at early years. Thessaloniki, Greece: D. Kyriakidis.

Griva, E., \& Chostelidou, D. (2017). CLIL in primary education: Promoting multicultural citizenship awareness in a foreign language classroom. Research Papers in Language Teaching and Learning, 8(2), 9-24.

Griva, E., \& Kofou, I. (2018). Alternative assessment in language learning: Challenges and practices. Thessaloniki, Greece: D Kyriakidis.
Jacobs, J. W. (1988). Euripides media: A psycodynamic model of severe divorce pathology. American Journal of Psychotherapy, 42(2), 308-319.

Johnson, W., \& Johnson, R. (1999). Learning together and alone: Cooperative, competitive, and individualistic learning. Boston, MA: Allyn - Bacon.

Kalantzis, M., \& Cope, B. (2012). Literacies. New York, NY: Cambridge University Press.

Kakridis, M., Kati, D., \& Nikiforidou, B. (1999).

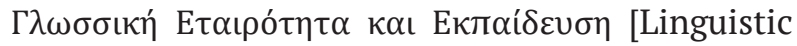
diversity and education]. In Glossikos Ypologistis. Retrieved from http://www.komvos.edu.gr/ periodiko/periodiko1st/default.htm

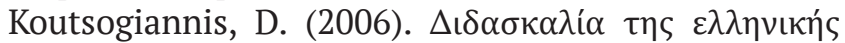

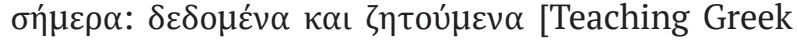
nowadays: Data and perspectives / requisites]. Studies on the Greek Language, 26, 233-251.

Kress, G., \& Van Leeuwen, T. (1996). Reading images: The grammar of visual design. London, UK: Routledge.

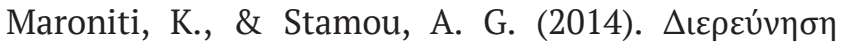

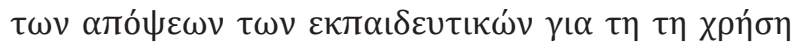

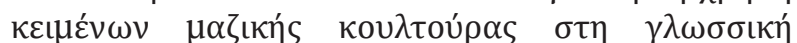
$\varepsilon \kappa \pi \alpha i ́ \delta \varepsilon v \sigma \eta$ [Exploration of teachers' ideas about the use of popular culture texts in language education]. Studies on the Greek Language, 34, 271284.

Maroniti, K., Stamou, A. G., Griva, E., Saltidou, R.

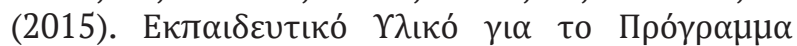

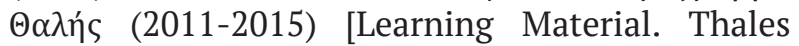
Project (2011-2015) 'Linguistic variation and language ideologies in popular culture texts: Design, development and assessment of learning material for critical language awareness]. Athens, Greece: Greek Ministry of Education.

Maroniti, K. Stamou, A. G., Griva, E., \& Dinas, K. (2016).

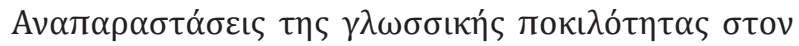

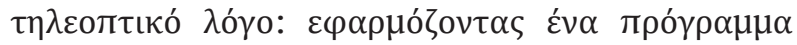

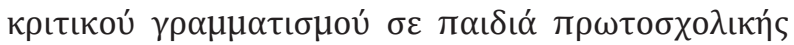
$\eta \lambda \iota \kappa i ́ \alpha \varsigma$ [Representations of sociolinguistic diversity in television discourse: Implementing a critical literacy project to primary school children of grade 1]. In A. G. Stamou, P. Politis \& A. Archakis (Eds.), Sociolinguistic diversity and critical literacies in popular culture discourse: Suggestions for language teaching (pp. 57-94). Kavala, Greece: Ekdoseis Saita.

Morrell, E. (2002). Toward a critical pedagogy of popular culture: Literacy development among urban youth. Journal of Adolescent and Adult Literacy, 46, 72-77.

Porter Ladousse, G. (1987). Role play. Oxford, UK: Oxford University Press.

Richards, J. C., \& Lockhart, C. (1994). Reflective teaching in second language classrooms. Cambridge, UK: Cambridge University Press.

Saltidou, T. P., \& Stamou, A. G. (2014). The mediation of 'youth language' in mainstream mass culture: 
Evidence from a Greek family sitcom. Sociolinguistic Studies, 8(2), 223-248.

Saltidou, T. P., \& Stamou, A. G. (2018). 'Cool children' and 'super seniors' cross into youth language: Humorous constructions of youthfulness in Greek family sitcoms. In V. Tsakona \& J. Chovanec (Eds.), The dynamics of interactional humor: Creating and negotiating humor in everyday encounters (pp. 181-204). Amsterdam, the Netherlands: John Benjamins.

Stamou, A. G. (2011). Speech style and the construction of social division: Evidence from Greek television. Language \& Communication, 31(4), 329-344.

Stamou, A. G. (2012). Representations of linguistic variation in children's books: Register stylization as a resource for (critical) language awareness. Language Awareness, 21(4), 313-329.

Stamou, A. G. (2014). A literature review on the mediation of sociolinguistic style in television and cinematic fiction: Sustaining the ideology of authenticity. Language \& Literature, 23(2), 118-140.

Stamou, A. G. (2018, June). Sociolinguistics of fiction. Discourse, Context \& Media, 23, 1-5.

Stamou A. G., Maroniti, K., \& Griva E. (2015). Young children talk about their popular cartoon and TV heroes' speech styles: Media reception and language attitudes. Language Awareness, 24(3), 216-232.

Stamou, A. G., Maroniti, K., \& Schizas, D. (2014). Greek young children's engagement with media in the home: Parents' and children's perspectives. Studies in Media and Communication, 2(2), 93-106.

Stevens, L. (2001). South Park and society: Instructional and curricular implications of popular culture in the classroom. Journal of Adolescent and Adult Literacy, 44, 81-97.

Stiggins, R. J. (1994). Student-centered classroom assessment. New York, NY: Merrill.

Tomlinson, B., \& Masuhara, H. (2009). Playing to learn: A review of physical games in second language acquisition. Simulation \& Gaming, 40(5), 645-668.

Vrinioti, K., \& Griva, E. (2015). 'Participation' as a collaborative learning process in first and second grade: A time-consuming process counteracting the achievement of cognitive learning. In K. Fischer, I. Kaschefi-Haude \& J. Schneider (Eds.), Strengthening activity-oriented interaction and growth in the early years and in transitions (pp. 81-101). Thessaloniki, Greece: The Signals Consortium, European Commission. Retrieved from http://www.signals-eu.com/

Willis, J. (1996). A framework for task-based learning. London, UK: Longman. 